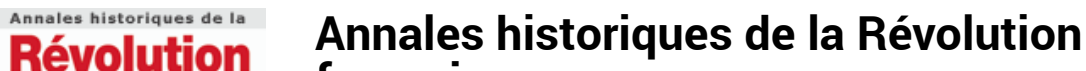

française française

333 | juillet-septembre 2003

Varia

\section{Isabelle HENRY, Dumouriez, général de la Révolution} (1739-1823)

Annie Crépin

\section{OpenEdition}

\section{Journals}

Édition électronique

URL : https://journals.openedition.org/ahrf/10817

DOI : 10.4000/ahrf.10817

ISSN : 1952-403X

\section{Éditeur :}

Armand Colin, Société des études robespierristes

Édition imprimée

Date de publication : 1 septembre 2003

ISSN : 0003-4436

\section{Référence électronique}

Annie Crépin, «Isabelle henRY, Dumouriez, général de la Révolution (1739-1823) », Annales historiques de la Révolution française [En ligne], 333 | juillet-septembre 2003, mis en ligne le 07 décembre 2009, consulté le 22 avril 2022. URL : http://journals.openedition.org/ahrf/10817 ; DOI : https://doi.org/ 10.4000/ahrf.10817

Ce document a été généré automatiquement le 22 avril 2022.

Tous droits réservés 


\title{
Isabelle HENRY, Dumouriez, général de la Révolution (1739-1823)
}

\author{
Annie Crépin
}

\section{RÉFÉRENCE}

Isabelle HENRY, Dumouriez, général de la Révolution (1739-1823), Paris, l'Harmattan, 2002, 520 p., ISBN 2-7475-2199-0, 41,13€.

1 Isabelle Henry a entrepris d'écrire la biographie du général Dumouriez dont elle est la descendante. Son ouvrage est essentiellement fondé sur des archives familiales et sur les Mémoires du général auxquels elle donne le ton d'un roman, non dépourvu parfois de facilités de plume. Il est vrai que ce style alerte et familier convient fort bien au récit de la jeunesse de Dumouriez et aux débuts de sa carrière aventureuse sinon d'aventurier.

2 L'histoire familiale de Dumouriez dénote une certaine originalité. S'il est fils d'un commissaire des guerres, issu d'une famille de la noblesse provençale, son grand-père paternel s'est engagé dans la troupe de Molière puis a fondé une entreprise de pompes à eau. A dix-huit ans, le futur général fait ses premières armes sur les champs de bataille de la guerre de Sept Ans où il a accompagné son père. Capitaine à vingt-quatre ans et décoré de la croix de Saint-Louis, il conçoit peu d'attraits pour la vie de garnison et, comme un projet de mariage avec une cousine est contrarié pendant de longues années, il sollicite du duc de Choiseul des missions à l'étranger qui satisfont son goût des voyages et de l'aventure tant elles sont à la limite de la diplomatie, de l'espionnage et de la préparation d'expéditions militaires. Tour à tour, il est en Italie, en Corse où il reviendra pendant la campagne de 1768, en Espagne, en Pologne et à Hambourg. Manifestant un talent certain pour l'écriture et doté d'un regard lucide, il inonde le ministre de mémoires. Des intrigues de cour, la disgrâce de son protecteur et ses propres imprudences épistolaires lui valent la Bastille pour quelques mois en 1773-1774, puis un internement au château de Caen. Libéré après la mort de Louis XV et 
devenu colonel, il réussit enfin à épouser sa cousine et entame une autre série de missions, notamment l'étude d'un projet de défense des côtes normandes ce qui lui vaut d'être nommé commandant de la ville de Cherbourg en 1778.

Autant les imbroglios polonais et suédois auxquels il s'est trouvé mêlé sont retracés avec bonheur, autant, dans les chapitres qui suivent consacrés au séjour de Dumouriez à Cherbourg, qui va durer une dizaine d'années, les défauts d'une narration à la limite de Anecdotique deviennent patents. Des chapitres entièrement consacrés aux réceptions que donne le ménage Dumouriez, reconstitués de manière romancée, prennent autant d'importance que ceux où est évoquée - avec une minutie certaine l'œuvre accomplie par Dumouriez à Cherbourg qui lui permet de devenir brigadier général en 1789. « Là, son génie actif s'exerce contre les éléments comme il s'est exercé contre les hommes » dira de lui Lamartine (p. 293).

4 Sa vie mouvementée va prendre un nouveau cours et son entregent certain trouver à s'exercer dans une époque grandiose dont les enjeux finissent par le dépasser. Cette époque aurait mérité un autre traitement. On ne saurait certes reprocher à cet ouvrage de ne pas sortir des limites de la biographie classique encore que certains auteurs aient renouvelé le genre. Mais déjà pour l'Ancien Régime Isabelle Henry aurait pu moins sommairement retracer le contexte: rien, ou presque, n'est dit, par exemple, des débats sur l'armée alors que Dumouriez était en relation avec Guibert. Ces défauts s'aggravent pour l'évocation de la période révolutionnaire qui relève d'une vision simpliste inspirée largement des clichés de Lenôtre, abondamment cité dans la bibliographie, tant à propos des situations - les assemblées révolutionnaires peuplées de "braillards" - qu'à propos des personnages - les portraits caricaturaux de Marat, de Sieyès ou du duc d'Orléans, entre autres.

5 Dumouriez, maréchal de camp à cinquante ans, devient commandant de l'armée du Nord mais c'est après son bref ministériat des Affaires étrangères, et postérieurement au 10 août, qu'il prend effectivement le commandement de cette armée où l'un de ses aides de camp est le futur Louis-Philippe. Les batailles de Valmy et de Jcmmapes sont retracées avec sobriété sans que l'auteur exagère le rôle de son personnage - qui fut important - et sans qu'elle cède à la légende dorée ou noire dont le premier combat fut l'objet. Mais les approximations voire les erreurs manifestes s'accumulent. Si, au commencement de l'ouvrage, le lecteur pouvait penser qu'une coquille faisait du duc et de la duchesse de Bourgogne les parents de Louis... XVI (p. 180), il est plus dubitatif sur Morris, ami de Dumouriez et... gouverneur (p. 317), sur les Fédérés marseillais qui auraient été les plus violents acteurs de la prise de la Bastille (p. 325) et sur l'origine brésilienne de Miranda (p. 371). Enfin, il est choqué de lire à la p. 412 que le lieutenantcolonel Alexandre Dumas qui sert en 1793 sous les ordres de Dumouriez n'est autre que le célèbre écrivain... né en 1802. D'autres exemples pourraient être donnés.

6 Après l'offensive vient le temps de la défaite consommée à Neerwinden à propos de laquelle l'auteur ne cache pas les erreurs du général. Elle lui prête l'intention de sauver le roi dès l'automne 1792 et, après la mort de celui-ci, de rétablir la monarchie par un coup d'État. Elle ne cache pas non plus les lettres provocantes qu'il écrit à la Convention. Ainsi se met en place l'engrenage qui le conduit à la trahison. Elle cite à ce propos le jugement lucide que le général portait sur lui-même : "Dumouriez n'avait point les qualités requises pour un chef de parti. II eût peut-être été bon général, bon ambassadeur dans un gouvernement tout formé, soit monarchique, soit républicain » (p. 427). 
7 Il mène désormais une vie d'errance à travers l'Europe tout en retrouvant les activités de sa jeunesse : l'écriture, puisqu'il rédige ses Mémoires d'abord publiés à Hambourg puis à Paris en l'an III, l'intrigue et les missions secrètes, puisqu'il ne renonce pas à jouer un rôle en faveur de son protégé, le duc d'Orléans. Mais les hauts personnages qu'il approche l'accueillent froidement, en le considérant, à l'instar de Wellington, comme intelligent et perspicace mais comploteur et intrigant. Installe en Angleterre en 1804, il y meurt en 1823 dans un relatif oubli. Ainsi s'achève la vie d'unhomme de talent mais dépourvu de l'envergure nécessaire pour maîtriser et imprimer sa marque aux événements qu'il traversa.

8 Le lecteur regrettera que cette biographie qui sait rendre le personnage attachant ne témoigne pas de la même rigueur pour rendre compte de la période dans laquelle il vécut et du recul nécessaire par rapport aux sources. Les sources imprimées qui sont citées ne sont d'ailleurs pas distinguées de la bibliogaphie proprement dite et on déplore l'absence d'un index et d'une chronologie. 